\title{
DES/FIANDO DIÁLOGOS SOBRE O CONCEITO DE CADEIA ALIMENTAR EM UMA AULA DE CIÊNCIAS NOS ANOS INICIAIS DO ENSINO FUNDAMENAL
}

\author{
SHEILA ALVES DE ALMEIDA ${ }^{*}$ \\ https://orcid.org/0000-0002-2030-5173 \\ GUILHERME DA SILVA LIMA ${ }^{* *}$ \\ https://orcid.org/0000-0002-0049-5790 \\ BÁRBARA LUIZA ALVES PEREIRA ${ }^{1 * * *}$ \\ https://orcid.org/0000-0001-5064-7214
}

RESUMO: Este trabalho analisa as estratégias utilizadas por uma professora no ensino do conceito de cadeia alimentar e os sentidos e significados produzidos pelas crianças em uma aula de Ciências nos anos iniciais do Ensino Fundamental. Com base em estudos sobre a linguagem, foram analisados dois eventos distintos realizados nessa aula que contemplam as interações verbais sobre o conceito de cadeia alimentar. Em um primeiro momento observouse a apresentação do conceito de cadeia alimentar pela professora e como as crianças produzem sentidos às palavras durante o processo de compreensão do conceito. No segundo, identificaram-se a apresentação de outros conceitos relacionados à temática da aula e as dificuldades que a compreensão do modelo de cadeia alimentar traz consigo. Assim, partindo de pressupostos bakhtinianos e da perspectiva histórico-cultural, a questão fundamental presente neste artigo é a discussão da natureza dialógica do processo de compreensão do conceito de cadeia alimentar. Palavras-chave: Dialogia. Cadeia alimentar. Ensino fundamental.

DES/HILANDO DIÁLOGOS ACERCA DEL CO CEPTO DE CADENA ALIMENTARIA EN UNA CLASE DE CIENCIAS EN LOS PRIMEROS AÑOS DE LA EDUCACIÓN BÁSICA

RESUMEN: Este trabajo analiza las estrategias que utilizó una profesora para enseñar el concepto de cadena alimentaria y los sentidos y significados que produjeron los niños en una clase de Ciencias en los primeros años de la Educación Básica. Basándose en estudios acerca

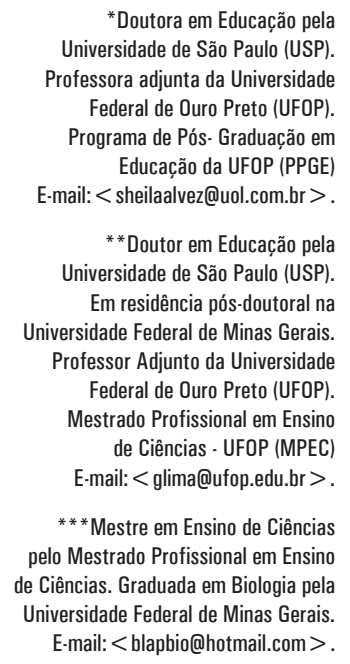

*Doutora em Educação pela Universidade de São Paulo (USP). Professora adjunta da Universidade Federal de Ouro Preto (UFOP). Programa de Pós- Graduação em Educação da UFOP (PPGE) E-mail:< sheilaalvez@uol.com.br>. * *Doutor em Educação pela Universidade de São Paulo (USP). Em residência pós-doutoral na Universidade Federal de Minas Gerais. Professor Adjunto da Universidade Federal de Ouro Preto (UFOP). Mestrado Profissional em Ensino de Ciências - UFOP (MPEC) E-mail:<glima@ufop.edu.br>.

***Mestre em Ensino de Ciências pelo Mestrado Profissional em Ensino de Ciências. Graduada em Biologia pela Universidade Federal de Minas Gerais. E-mail:<blapbio@hotmail.com>. 
del lenguaje, se analizaron dos eventos distintos realizados en esa clase que contemplan las interacciones verbales acerca del concepto de cadena alimentaria. En un primer momento se observó la presentación del concepto de cadena alimentaria por la profesora y cómo los niños producen sentidos para las palabras durante el proceso de compresión del concepto. En el segundo se identificaron la presentación de otros conceptos relacionados con la temática de la clase y las dificultades que la comprensión del modelo de cadena alimentaria implica. Así, partiéndose de presupuestos bajtinianos y de la perspectiva histórico-cultural, la cuestión fundamental presente es este artículo es la discusión de la naturaleza dialógica del proceso de comprensión del concepto de cadena alimentaria.

Palabras clave: Dialogía. Cadena alimentaria. Educación básica.

\section{SHREDDING DIALOGUES ON THE FOOD CHAIN CONCEPT IN A SCIENCE CLASS IN THE EARLY YEARS OF FUNDAMENTAL EDUCATION}

ABSTRACT: This work analyzes the strategies used to teach the concept of the food chain and the production of sense and meanings by children in a science class in the early years of elementary school. Based on studies on language, we analyzed two distinct events that contemplate the verbal interactions about the concept of the food chain in a classroom. First, we highlight the presentation of the concept of the food chain by the teacher and how children produce meanings to words during the process of understanding. In the second event, we identified the presentation of other concepts related to the theme of the class and the difficulties that the understanding of the food chain model entails. Thus, starting from bakhtinian presuppositions and from historical-cultural theory, the fundamental question presented in this article is the discussion of the dialogical nature of the process of understanding the food chain concept.

Keywords: Dialogue. Food chain. Elementary school. 


\section{INTRODUÇÃO}

Os processos comunicativos constituem as principais ferramentas do professor na proposição e condução das atividades educativas. Assim, embora haja diversas ferramentas que contribuem com a educação científica como os livros didáticos, experimentos, atividades de campo, softwares, jogos etc., todos esses suportes carecem de interações comunicativas. Tal fato não cria, necessariamente, uma relação hierárquica entre os suportes mediacionais utilizados nos processos de ensino e aprendizagem, contudo evidencia que a linguagem é primordial na maioria das atividades educacionais.

Nas atividades de ensino, a importância da comunicação é evidente, já que o professor utiliza a interação para propor e conduzir atividades e explicar conteúdos. Vygotsky, no início do século XX, chamou a atenção para a importância da linguagem para a aprendizagem e o desenvolvimento humano.

Com efeito, pesquisadores do campo do Ensino de Ciências têm se debruçado há décadas para compreender os processos comunicativos que promovem a educação científica a fim de repensar e propor estratégicas específicas para as atividades educativas. Tais contribuições contemplam os diversos procedimentos comunicativos adotados em sala de aula, citam-se nesse caso: as interações verbais entre os estudantes e professores, a narrativa, a produção argumentativa e a comunicação não verbal por meio de gestos (MEHAN,1979; LEAL; GOUVEA, 2000; MORTIMER; SCOT'T, 2002; LIMA, AGUIAR e CARO, 2011, ALMEIDA, 2011; IBRAIM; MENDONÇA; JUSTI, 2013; GIORDAN; SILVA NETO; AIZAWA, 2015).

Seguindo os pressupostos dos autores supracitados, tornando visíveis as práticas discursivas na sala de aula, busca-se neste artigo investigar as estratégias da professora ao ensinar o conceito de cadeia alimentar em uma aula do $3^{\circ}$ ano do ensino fundamental. Pretende-se ainda, analisar os processos de produção de sentidos realizados pelos estudantes. Para isso, a pesquisa está fundamentada em duas cenas de uma aula de Ciências sobre o conceito cadeia alimentar. Tais resultados podem contribuir para a elaboração e reflexão dos docentes sobre estratégias de ensino e a condução de atividades educativas e produção da narrativa. Para tanto, este trabalho se baseia nas contribuições de Vygotsky acerca dos conceitos científicos e espontâneos e de Bakhtin sobre a natureza da linguagem e da comunicação.

\section{O PROCESSO DE FORMAC̣ÃO DE CONCEITOS NA PERSPECTIVA DA TEORIA HISTÓRICO-CULTURAL}

Para Vygotsky, a apropriação do conhecimento ocorre por meio da mediação social. Em sua visão, é através dos outros que o ser humano estabelece relações com os objetos de conhecimento. Esclarece Vygotsky (1991) que a linguagem é indispensável à formação e apropriação de conceitos.

A compreensão do conceito, por sua vez, ocorre à medida que o sujeito correlaciona um signo interior, portanto já dominado, com outros signos ${ }^{1}$ que são enunciados no contexto comunicativo (BAKHTIN, 2000). Nesse processo, o sujeito realiza uma série de correlações entre os signos que já domina com aqueles que estão em processo de compreensão a fim de estabelecer sentidos e estabilizar significações coerentes acerca do novo signo (BAKHTIN, 2000). 
Vygotsky (2009), ao analisar a aprendizagem e o desenvolvimento infantil, distingue dois tipos de conceitos: os conceitos espontâneos e os conceitos científicos. Os conceitos espontâneos são aprendidos desorganizadamente. Segundo Vygotsky, trata-se de uma reflexão assistemática do sujeito sobre suas experiências. Os conceitos científicos, por seu turno, são estruturados hierarquicamente por meio de relações lógico-abstratas, além de serem aprendidos pelas crianças através da educação formal (CASTRO; BEJARANO, 2013). Nas palavras de Vygotsky (1991: 219):

O nascimento dos conceitos científicos começa não com um encontro imediato com coisas, mas com um relacionamento mediato para um objeto. Com o conceito espontâneo a criança se move das coisas para o conceito. Com os conceitos científicos ela é forçada a seguir a trajetória oposta - do conceito para as coisas.

Conforme Vygotsky, são os outros que auxiliam a criança a dar sentido ao mundo. Os conceitos permitem uma interação entre sujeito e objeto que é própria dos seres humanos. Sejam espontâneos ou científicos, o conceito é usado como instrumento mediador entre a criança e o objeto. Eles são compreendidos pelas crianças, predominantemente, por meio da interação delas com outros sujeitos.

Os conceitos espontâneos e os conceitos científicos nem sempre são conflitantes. Embora se desenvolvam em direções opostas, podem articular-se dialeticamente e fazer parte de um mesmo processo. Para Vygotsky (1991: 93):

o desenvolvimento dos conceitos espontâneos da criança é ascendente, enquanto o desenvolvimento dos seus conceitos científicos é descendente [...] a sua evolução faz com que terminem por se encontrar [...] os conceitos científicos desenvolvem-se para baixo por meio dos conceitos espontâneos; o conceitos espontâneos desenvolvem-se para cima por meio dos conceitos científicos.

Dessa forma, um conceito espontâneo pode corroborar a formação de um conceito científico sobre o mesmo objeto à medida que se desenvolve no sentido da abstração. O movimento descendente dos conceitos científicos, por sua vez, produz estruturas que permitem o seu desenvolvimento por meio da incorporação de elementos concretos. As contribuições de Vygotsky evidenciam que a aprendizagem não consiste na memorização ou verbalização de um conjunto de definições. Nesse sentido, as definições não deveriam ser ponto de partida no processo de ensino. Para Vygotsky (1991, p. 72),

a experiência prática mostra que o ensino direto de conceitos é impossível e infrutífero. Um professor que tenta fazer isso geralmente não obtém qualquer resultado, exceto o verbalismo vazio, uma repetição de palavras pela criança, semelhante à de um papagaio, que simula um conhecimento dos conceitos correspondentes, mas que na realidade oculta um vácuo.

Assim, a aprendizagem de conceitos requer elementos que vão além de uma definição abstrata. Para Bakhtin (1981, p. 73), a "compreensão implica num processo de produção de contrapalavras vinculadas às palavras do interlocutor". 
Bakhtin destaca que o significado das palavras é concebido por um processo ativo e dinâmico entre os sujeitos que participam da interação social, portanto não deveria ser interpretado como uma unidade estática. Os significados, portanto, são produzidos pelos sujeitos somente quando relacionados com outros significados, ou seja, o significado não é produzido por meio do seu isolamento, ele é concebido no interior da interação social.

\section{O CONCEITO DE CADEIA ALIMENTAR}

Segundo os livros didáticos de Ciências, em geral, "cadeia alimentar é uma sequência de organismos em que um serve de alimento para o outro, a partir do produto" (OLIVEIRA et al., 2003, p. 8). Essa sequência em que um ser vivo serve de alimento para outro é frequentemente representada por diagramas de uma rede alimentar ou trófica nos livros didáticos. Essas representações são descrições gráficas das possíveis e diversas relações alimentares entre indivíduos de diferentes espécies em uma comunidade biológica.

À guisa de esclarecimento, nos diagramas, as imagens ou nomes dos organismos são ligados por setas representando níveis de uma pirâmide de energia. As plantas são alimento dos herbívoros; os herbívoros são alimento de carnívoros, podendo estes ser alimento de animais carnívoros maiores.

Apesar da frequência dessa representação, vários pesquisadores têm criticado a forma pela qual esse conceito é apresentado nos livros didáticos (PAZ et al., 2006; SILVA; MASKIEWICZ, 2016; HARTWEG et al., 2017). Argumentam que se trata de uma "representação sequencial linear, a partir de um vegetal, sugerindo que os animais menores são consumidos pelos maiores durante a sua alimentação para a sua sobrevivência" (PAZ et al., 2006, p. 162). Ao analisar ilustrações sobre o conceito de cadeias e teias alimentares presentes em livros didáticos, Pereira e Carvalho (2013, p.7) ressaltam que:

os livros normalmente iniciam o conteúdo a partir dos modelos contidos nas fotos e desenhos, tentando retratar uma sequência de seres vivos que se relacionam na natureza em busca de alimentação e condições favoráveis à sobrevivência. Cada ilustração, portanto, configura um modelo teórico e hipotético que representa o comportamento dos seres vivos.

Contudo, as cadeias alimentares estão longe da simplicidade esquemática com que se costuma apresentá-las em materiais didáticos, pois as relações alimentares se entrecruzam de forma variada, constituindo redes complexas, também conhecidas pelo termo teias alimentares. A presença de modelos questionáveis também foi identificada por pesquisadores de outras nacionalidades. Para Hartweg e colaboradores (2017), por exemplo, esse modelo de cadeia alimentar a princípio parece simples, porém os ecossistemas são complexas redes que envolvem diversas variáveis e são estruturas que nem sempre podem ser observadas diretamente. De acordo com Silva e Maskiewicz (2016, p. 635, tradução livre), "precisamos ajudar os estudantes a ver as cadeias alimentares como sistemas dinâmicos, ao invés de ver as interações entre espécies apenas como relações diretas de causa e efeito". 
Nas cadeias alimentares, a transferência de energia é um aspecto fundamental a ser discutido com os alunos, pois uma cadeia alimentar é também uma representação de um ciclo de matéria (PAZ et.al 2006). Nos Parâmetros Curriculares Nacionais, a complexidade desse conteúdo é afirmada no seguinte excerto:

\begin{abstract}
As interações alimentares podem ser representadas através de uma ou várias sequências, cadeias e teias alimentares, contribuindo para a consolidação do conceito em desenvolvimento e para o início do entendimento da existência de um equilíbrio dinâmico nos ecossistemas, em que matéria e energia transitam de formas diferentes - em ciclos e fluxos respectivamente - e que tais ciclos e fluxos representam formas de interação entre a porção viva e a abiótica do sistema (BRASIL, 2000, p. 17).
\end{abstract}

Em sala de aula, é comum o professor iniciar o "conteúdo a partir de um modelo, tendo implícita a "organização" de uma sequência de seres vivos que se relacionam de forma natural em busca de alimento à sua sobrevivência" (PAZ et.al 2006, p. 162-163).

Ao discorrer sobre o ensino do conceito de cadeia alimentar, Lacreu (1998) destaca que nos livros didáticos de Ciências e em situações de aprendizagem notase uma preocupação especial em definir e aplicar os seguintes termos: produtores, consumidores, carnívoros e herbívoros. No entanto, as definições nem sempre apresentam uma significação precisa e sistemática. Para essa autora, a ausência de referência à matéria morta e, muitas vezes, aos microrganismos constitui um entrave para a compreensão global do conceito de ecossistema e do conceito de cadeia alimentar (LACREU, 1998).

Oliveira e colaboradores (2003, p.10) acrescentam que "as crianças têm conhecimento que na natureza os seres vivos se relacionam em função do tipo de alimento e que os organismos maiores normalmente consomem os menores". Tais relações, inclusive, podem induzir interpretações erradas. Por sua vez, Gallegos e colaboradores (1994) argumentam que crianças possuem preconcepções que associam os carnívoros aos animais maiores e ferozes e os herbívoros aos animais menores e dóceis. Na visão desses autores, as preconcepções das crianças são baseadas na relação predador-presa, pois são elementos mais próximos de suas vivências cotidianas (GALLEGOS; JEREZANO; FLORES, 1994).

Em adição, conforme Oliveira e colaboradores, os sentidos produzidos pelas crianças estão baseados em suas experiências cotidianas, nas palavras dos autores "as observações que as crianças realizam no meio e as construções que essas tecem sobre o mundo onde vivem, originam concepções que permitem a elas, muitas vezes, realizar previsões e explicar fenômenos que o cercam" (OLIVEIRA et al.,2003, p. 10). Embora seja possível que as crianças tenham observado, em algum momento, um quintal gramado com formigas, borboletas, pulgões e pássaros, provavelmente elas não os observaram como produtores, consumidores ou como cadeias alimentares, ou ciclo de matéria e fluxo de energia. As cadeias alimentares são representações de processos atemporais, produzidos teoricamente para explicar as trocas de matéria e energia em um ecossistema. Sendo assim, o ensino desse conceito deve ser orientado de modo que as crianças reconheçam as generalizações que representam a realidade e entendam os limites e possibilidades desses modelos. 


\section{METODOLOGIA}

Com o objetivo de analisar a atribuição de sentidos e significados ao conceito de cadeia alimentar, recorreu-se a uma aula singular extraída dos dados não analisados da dissertação de mestrado Recepção e uso de livro de apoio ao professor dos anos iniciais: um estudo de caso do livro "Trilhas para Ensinar Ciências para Crianças" (PEREIRA, 2017). O projeto de pesquisa dessa dissertação foi submetido ao Conselho de Ética em Pesquisa e aprovado. A professora e todos os responsáveis pelas crianças assinaram o termo de consentimento livre e esclarecido para participar da investigação, no qual foram descritos os procedimentos de registro e a garantia da não identificação dos sujeitos de pesquisa quando da publicação dos resultados.

A escola, na qual a pesquisa foi desenvolvida, pertence à Rede Municipal da cidade de Mariana e recebe, durante manhã e tarde, aproximadamente 800 alunos da Educação Infantil, Ensino Fundamental I e II, e alunos jovens e adultos. Situada em um bairro da periferia, a maioria das crianças dessa escola são assistidas por programas sociais. A escola foi indicada pela Secretaria Municipal de Educação sob a alegação de que era aberta à participação de pesquisas da universidade.

Quanto à escolha da sala de aula e da professora, seguiram-se alguns critérios importantes para a realização da pesquisa, como: autorização para filmagens das aulas concedida pelos responsáveis pelas crianças e pela professora; disposição da professora para trabalhar com determinado tema do livro de apoio ao professor. Tratava-se de uma professora que atuava nos anos iniciais do ensino fundamental há 19 anos e era formada em Pedagogia há mais de dez anos. Ela era responsável pelos conteúdos de Matemática e Ciências e lecionava para quatro turmas, trabalhando duas horas-aula semanais em cada uma delas. A pesquisa foi realizada em uma turma do $3^{\circ}$ ano, indicada pela professora, composta por 20 alunos com idade entre 9 e 10 anos. A justificativa da professora para a escolha da turma foi o engajamento e a participação das crianças nas aulas.

Assim sendo, as aulas de Ciências dessa turma foram filmadas durante um mês e meio, perfazendo um total de 12 horas de filmagens que foram ordenadas por data. Após cada filmagem, seguiam-se os seguintes procedimentos: assistir aos registros repetidas vezes, com o objetivo de observar a prática pedagógica da professora; elaborar mapas de ações identificando as interações discursivas entre os sujeitos; elaborar mapas das formas de uso do livro; registrar o tempo transcorrido e as observações de campo (PEREIRA, 2017). Analisados os mapas foi selecionada uma aula em que a professora trabalhou o conceito de cadeia alimentar, considerado de baixa complexidade por ela. O estudo dessa aula indiciou que o tema escolhido inaugura um conflito de vozes acerca do conceito estudado. Assim, a presente pesquisa interessa compreender as estratégias utilizadas pela professora para ensinar o conceito de cadeia alimentar, bem como dos sentidos e significados que circularam durante a aula.

Quanto à análise da interação em sala de aula, baseou-se nas contribuições da psicologia histórico-cultural e na teoria da enunciação proposta por Bakhtin e o Círculo. Ambas as correntes teóricas consideram as atividades dos sujeitos como socialmente orientadas, mediadas pela linguagem vista também como fruto 
de interações sociais. Além disso, utilizou-se a análise microgenética (GÓES, 2000) para investigar os sentidos e significados produzidos pelas crianças e pela professora no decorrer do diálogo sobre o conceito cadeia alimentar.

\section{RESULTADOS E ANÁLISES}

A aula de Ciências, então analisada, sobre o conceito de cadeia alimentar foi realizada no último horário do dia. Após o sinal para a troca de professores, a professora entrou na sala, cumprimentou as crianças e se posicionou à frente da turma para falar aos estudantes. As palavras de ordem: "vamos lá pessoal, guardem o material de matemática e vamos para ciências" indicaram o início da aula que foi compreendido pelas crianças como um sinal de atenção. Em seguida, ela anunciou o tema da aula.

Parte dessa aula está apresentada nos quadro 1 a seguir e quadro 2 (p. 15). As transcrições das falas foram organizadas em turnos que indicam sequências discursivas enunciadas pelos sujeitos objetos da pesquisa. Assim as transcrições dos episódios privilegiam as interações entre os sujeitos que se expressam durante o processo de ensino e aprendizagem, totalizando 79 turnos de fala, divididos em duas sequências. Na primeira sequência (Quadro 1) - turno 1 a 41 -, são apresentados o conceito de cadeia alimentar pela professora e a compreensão das palavras pelas crianças acerca do conceito. Na sequência 2 (Quadro 2) - turno 42 a 79 -, o foco discursivo são interações relacionadas aos conceitos de produtores, herbívoros, carnívoros e decompositores; bem como a tentativa de síntese dos conceitos apresentados. Veja-se então, a primeira sequência: ${ }^{2}$

Quadro 1. Cadeia alimentar

\begin{tabular}{|c|c|c|c|}
\hline Turno & Participante & Discurso & Comentário \\
\hline 1 & Professora & $\begin{array}{l}\text { vamos lá pessoal }(. . .) \text { guardem o material } \\
\text { de matemática e vamos para ciências }\end{array}$ & \\
\hline 2 & Laís & professora, é para pegar o livro? & \\
\hline 3 & Professora & $\begin{array}{l}\text { não (...) senta lá que eu vou explicar (...) ei } \\
\text { Alex já guardou o caderno de matemática? } \\
\text { (...) bom gente eu quero que vocês façam } \\
\text { fileiras de duplas (...) uma aqui outra aqui } \\
\text { e a outra aqui (...) sem confusão gente }\end{array}$ & $\begin{array}{l}\text { Aponta aonde os } \\
\text { alunos devem } \\
\text { posicionar as } \\
\text { carteiras. A } \\
\text { professora solicita } \\
\text { que as crianças } \\
\text { se organizem em } \\
\text { duplas para um } \\
\text { jogo no fim da aula }\end{array}$ \\
\hline 4 & & & $\begin{array}{l}\text { Organização da } \\
\text { turma }\end{array}$ \\
\hline 5 & Professora & $\begin{array}{l}\text { então vamos lá (...) hoje vamos aprender } \\
\text { sobre cadeia alimentar (...) vocês sabem } \\
\text { o que é? }\end{array}$ & \\
\hline
\end{tabular}




\begin{tabular}{|c|c|c|c|}
\hline Turno & Participante & Discurso & Comentário \\
\hline 6 & Alan & uai (...) é de comer & \\
\hline 7 & Laís & é sobre os alimentos & \\
\hline 8 & Felipe & MAS CADEIA? (...) cadeia é cadeia de (...) & $\begin{array}{l}\text { Faz o sinal do } \\
\text { xadrez com as } \\
\text { mãos... a turma dá } \\
\text { risadas. }\end{array}$ \\
\hline 9 & Professora & $\begin{array}{l}\text { (...) então, tem uma joaninha lá no jardim } \\
\text { da minha casa, essa joaninha está se } \\
\text { alimentando da folha (...) porém logo } \\
\text { aqui tem um passarinho que vai ali e se } \\
\text { alimenta da (...) }\end{array}$ & $\begin{array}{l}\text { A professora } \\
\text { desenha uma } \\
\text { joaninha próxima } \\
\text { a uma folha e um } \\
\text { pássaro }\end{array}$ \\
\hline 10 & Camila & joaninha & \\
\hline 11 & Laís & da folha & \\
\hline 12 & Alan & não (...) da minhoca & \\
\hline 13 & Professora & $\begin{array}{l}\text { o passarinho neste caso vai se alimentar } \\
\text { da joaninha e será que vem alguém comer } \\
\text { o passarinho? }\end{array}$ & \\
\hline 14 & Alunos & VEM & Falam juntos \\
\hline 15 & Professora & vem? & \\
\hline 16 & Alex & ah (...) não sei & \\
\hline 17 & Felipe & uma cobra & \\
\hline 18 & Isadora & o gato & \\
\hline 19 & Professora & $\begin{array}{l}\text { nessa nossa cadeia alimentar aqui } \\
\text { ninguém vai comer o passarinho (...) ele } \\
\text { vai morrer }\end{array}$ & \\
\hline 20 & Alunos & & Risos \\
\hline 21 & Professora & $\begin{array}{l}\text { mas quando ele morre, o que acontece } \\
\text { com ele? }\end{array}$ & \\
\hline 22 & Alan & eu sei $(. .$.$) enche de formiga$ & \\
\hline 23 & Professora & (...) e o que mais acontece? & \\
\hline
\end{tabular}




\begin{tabular}{|c|c|c|c|}
\hline Turno & Participante & Discurso & Comentário \\
\hline 24 & Felipe & ele apodrece (...) ou um rato come & \\
\hline 25 & Professora & $\begin{array}{l}\text { ele é decomposto por bactérias e fungos } \\
\text { (...) nós não vemos mas elas estão por aí } \\
\text { não estão? }\end{array}$ & \\
\hline 26 & Alunos & $\operatorname{sim}$ & \\
\hline 27 & Professora & $\begin{array}{l}\text { então }(. . .) \text { isso que eu fiz aqui no quadro } \\
\text { é uma cadeia alimentar, agora vamos } \\
\text { entender melhor }\end{array}$ & $\begin{array}{l}\text { A professora } \\
\text { desenha } \\
\text { setas entre os } \\
\text { organismos }\end{array}$ \\
\hline 28 & Vitor & eu já matei um rato & \\
\hline 29 & Laís & o rato traz doença não é? & \\
\hline 30 & Professora & $\begin{array}{l}\text { gente }(. . .) \text { olha aqui }(. . .) \text { qual foi o primeiro } \\
\text { item que eu falei dessa cadeia alimentar? }\end{array}$ & $\begin{array}{l}\text { Aponta novamente } \\
\text { para o desenho no } \\
\text { quadro. }\end{array}$ \\
\hline 31 & Laís & a joaninha? & \\
\hline 32 & Professora & foi? foi Tiago? & \\
\hline 33 & Tiago & foi & \\
\hline 34 & Professora & mas o que a joaninha come? & \\
\hline 35 & Tiago & ah (...) a folha da planta & \\
\hline 36 & Professora & $\begin{array}{l}\text { ISSO (...) vamos falar dos vegetais, nós } \\
\text { comemos vegetais certo? verduras, frutas, } \\
\text { folhas... não é? }\end{array}$ & \\
\hline 37 & Alunos & SIM & \\
\hline 38 & Professora & $\begin{array}{l}\text { então (...) esses vegetais são os } \\
\text { produtores da cadeia alimentar (...) eles } \\
\text { utilizam a energia do sol e gás carbônico } \\
\text { do ar para produzirem seu próprio } \\
\text { alimento, vocês lembram? já vimos isso, } \\
\text { que nome se dá a esse processo? }\end{array}$ & \\
\hline 39 & Alan & clorofila... & \\
\hline 40 & Professora & não senhor (...) pensa aí (...) & \\
\hline 41 & Carolina & fotossíntese & \\
\hline
\end{tabular}


Como mostra o quadro 1, nesse episódio, com 41 turnos, a voz da professora apareceu em 17 turnos. Os alunos aparecem em 22 turnos, na maioria das vezes, respondendo às perguntas da professora. As produções orais das crianças são curtas e o conceito é apresentado em uma relação de causa e efeito.

No turno 5, após anunciar o tema da aula, a professora apresenta o conteúdo a ser estudado e, ao mesmo tempo, encoraja as crianças a demonstrar seus conhecimentos sobre o conceito. Dois alunos se prontificaram a falar relacionando o conceito às palavras de sua familiaridade: "é de comer; é sobre alimentos". Mas, no turno 8, um aluno contesta a resposta dos colegas quando apresenta dúvidas em relação às palavras cadeia e alimento. Além da linguagem verbal, esse aluno representa, com gestos, um xadrez como auxílio na elaboração dos significados que ele atribui à palavra. Possivelmente pelo contexto, uma aula de ciências, a turma acha engraçado o destaque da palavra "cadeia" pelo aluno. Essas interações evidenciam a multiplicidade de significações das palavras e é indício de uma interação polifônica. Apesar da dúvida explicitada pelo aluno, não houve contraposição dos sentidos gerados das palavras e do gesto. Possivelmente, a compreensão da palavra cadeia em uma aula de Ciências foi o primeiro obstáculo que os alunos deveriam transpor. Isso evidencia a necessidade de problematizar a sintaxe e a semântica envolvidas nos conceitos científicos de ciências, tornando-os objeto de ensino.

Em suma, as relações estabelecidas pelos estudantes nos turnos 5, 6, 7 e 8 mostram o início do processo de produção de sentidos. Os estudantes relacionam ao termo "cadeia alimentar" os signos e sentidos que já se apropriaram em suas experiências pessoais. Os três estudantes produzem sentidos decompondo o termo "cadeia alimentar". Alan e Laís focam a palavra alimentar e Felipe destaca a palavra cadeia. Tal fato indica que a primeira tentativa de produzir sentidos aos conceitos científicos se deu por meio da decomposição dos termos e da associação às palavras que já dominavam. Trata-se do uso de conceitos espontâneos por parte das crianças para tentarem entender o conceito científico apresentado pela professora.

A estratégia utilizada pelos estudantes mostra como as experiências e os conceitos espontâneos atuam na mediação para compreender algo novo. A decomposição e associação são etapas comuns para a produção de complexos, ao passo que as relações entre as palavras indicam modos de interagir com o conhecimento e o mundo. Enquanto o termo alimentar é vinculado diretamente à categoria de alimentos, o termo cadeia é vinculado ao espaço de cerceamento da liberdade de infratores e não à ideia de sucessão.

Neste ponto, para os estudantes, o termo ainda não possui significações estabilizadas, fato que é uma das características do processo de aprendizagem. Como se vê, eles disputam os sentidos de igual para igual, induzindo o início de uma interação polifônica. É importante ressaltar aqui a atuação da professora, que intervém nos próximos turnos visando orientar a produção de sentidos. Mas neste momento, as relações entre os sujeitos não são equivalentes, portanto não há a manutenção da polifonia nas interações, mas sim tentativas de estabelecer uma interação monológica para estabilizar o sentido do conceito científico.

No turno seguinte (9), a professora enquanto desenha uma cadeia alimentar no quadro, tenta construir uma narrativa, destacando situações próximas às experiências das crianças para abordar o conceito. Nessa estratégia, o conceito 
é representado em uma linguagem verbo-visual em que seres vivos de diferentes espécies aparecem em uma sequência simplificada: o pássaro se alimenta da joaninha que se alimenta da folha. O exemplo da professora sugere uma relação de presa e predador porque o viés da dependência alimentar não destaca a sucessão de níveis, mas de um animal maior se alimentando de um animal menor. De acordo com Oliveira e colaboradores (2003, p. 5), "tal concepção, ainda pode ser relacionada a um juízo de valores que atribui o papel de vítimas aos herbívoros e de vilões aos predadores".

Porém, nos turnos 10, 11 e 12, as respostas das crianças com referência à alimentação do pássaro indicam que as relações apresentadas pela professora reduzem ou excluem as inter-relações entre outros seres vivos, pois para as crianças o pássaro pode se alimentar da joaninha, da folha ou da minhoca. Tais resultados dialogam com as conclusões de Webb e Boltt (1990), uma vez que, para esses, os estudantes com idades entre 14 e 16 anos tendem a indicar caminhos alternativos e elos de predador e presa. Os caminhos alternativos são evidentes nos turnos 11 e 12, embora estabeleçam apenas uma relação, o que é compreensível por serem estudantes do ensino fundamental I. Já a relação presa e predador é observada nos turnos 10 e 12. Os resultados aqui apresentados avançam à medida que indicam o processo de produção de sentido e não somente interpretações dos estudantes. Afinal, essas interpretações já estão presentes nos anos iniciais da educação básica. Ressalta-se, ainda, que a relação indicada no turno 12 inclui elementos que não foram apresentados anteriormente. Trata-se de uma ação propositiva que indica uma relação arbitrária feita pelo estudante, condição que indica a compreensão e a autonomia para a produção de vínculos concretos entre os elementos.

Concluindo, os sentidos expressos pelas crianças nos turnos 10, 11 e 12 possivelmente têm origem na observação, isto é, em algum momento os estudantes observaram um pássaro se alimentando de diferentes espécies de animais e plantas. Embora não identifiquem nessa situação uma relação trófica, eles indicam uma relação alimentar em rede, com diferentes combinações. E, afinal, no turno 13, a professora adota um único ponto de vista para legitimar apenas um vínculo da cadeia: o pássaro comendo a joaninha. Nesse caso, ela não incorpora as complexas relações oriundas das respostas das crianças que mostram elementos da realidade.

Ainda no turno 13, a professora pergunta às crianças se seria possível outros animais comerem o pássaro. A aula persiste no viés de dependência alimentar entre presas e predadores e as crianças relacionam os animais em ordem hierárquica. Afirmam que um gato ou uma cobra poderiam ser predadores do pássaro. Neste ponto, a professora disciplina o discurso das crianças ditando-lhes, no turno 19, que o pássaro vai morrer. O turno seguinte mostra que as crianças acham engraçado a afirmativa da professora, pois a interação acaba sendo um jogo em que o aluno precisa adivinhar o que a professora espera ouvir. Contudo, ela pergunta às crianças o que vai ocorrer com o pássaro quando ele morrer. $\mathrm{E}$, nos turnos 22 e 24, os alunos, mais uma vez, baseados em suas experiências cotidianas, afirmam que o pássaro ficaria cheio de formiga, seria comido por um rato ou que apodreceria. Possivelmente, as crianças identificam as formigas e ratos como decompositores, associando esses animais a eventos negativos. A associação desses animais à categoria de decompositores, não implica em uma compreensão 
organizada hierarquicamente, tais como os conceitos científicos, parece que se trata de uma observação baseada em conceitos espontâneos. $\mathrm{O}$ apodrecimento do pássaro é uma situação evidenciada por um aluno que não demonstra compreender a ação dos decompositores nesse processo. Mas, a resposta dele poderia ser uma contribuição importante para a explicação do ciclo da matéria.

E, então, no turno 25 a professora explica que o pássaro pode ser decomposto por fungos e bactérias. Embora ela não converse com as crianças sobre esse processo, a menção a microrganismos que se alimentam de detritos é importante porque, na maioria das vezes, os decompositores não são mencionados quando se trata da discussão dos níveis tróficos na sala de aula (PAZ et al. 2006).

Prosseguindo a aula, no turno 27 , a professora inclui setas em seu desenho e denomina a sua representação como cadeia alimentar. A partir desse turno, ela retoma, com as crianças, o conceito baseado em relações unívocas entre os animais e plantas. Além de nomear de maneira linear e sequencial os organismos, ela nomeia cada indivíduo que representa os diferentes níveis da cadeia. As relações são representadas por setas que indicam que cada organismo é "comido por", de acordo com o sentido da seta, embora ela não explique às crianças o que as setas representam no desenho. Os decompositores não aparecem na representação nem são mencionados nesse turno. Em seguida, no turno 28 , uma criança ressalta que já matou um rato, possivelmente atribuindo à cadeia alimentar o sentido de extermínio e predação. E, desviando a linearidade da narrativa, tece um comentário paralelo que tem vínculo com o enunciado de Felipe no turno 24. O desvio da narrativa se mantém no turno 29, quando Laís comenta sobre a transmissão de doenças pelos ratos. A introdução de elementos da realidade que excedem as relações apresentadas pela professora mostra que o pensamento das crianças divaga por campos amplos, indicando caminhos alternativos e complexos para a discussão do tema.

Observa-se, no turno 30, a retomada da linearidade da narrativa marcada pelo início da apresentação dos conceitos produtores, herbívoros e carnívoros, indicando uma hierarquia entre os níveis e excluindo os decompositores. Nesse turno, a professora não define para as crianças esses conceitos, mas recorre mais uma vez ao modelo verbo-visual produzido para ensiná-las. Depois de perguntar aos alunos qual era o primeiro item da cadeia alimentar que ela havia mencionado, buscando evidenciar os produtores que estão na base da cadeia alimentar, eles, ignorando o modelo e, consequentemente o papel dos produtores que foi pouco discutido na aula, respondem que era a joaninha (turno 31). Nota-se que a resposta das crianças é coerente com a pergunta da professora, tendo em vista que, temporalmente, o primeiro item ao qual a professora se referira era a joaninha. Nesse caso, o modelo apresentado pela professora e a expressão verbal não parecem coincidentes.

No turno 34, a professora altera a pergunta direcionando a questão para a alimentação das joaninhas. Após a resposta esperada de um aluno, turno 35, a professora, turno 38, introduz o conceito de produtores e explica porque são chamados de produtores: "eles utilizam a energia do sol e gás carbônico do ar para produzirem seu próprio alimento”. Os produtores só são mencionados na ocasião da alimentação das joaninhas e quando a professora identifica esse nível. Isso indica a pouca importância dada aos vegetais para a manutenção da vida e como produtores da maior parte orgânica dos ecossistemas. 
Como as explicações apresentadas às crianças ficam restritas às relações alimentares entre os organismos, a professora não evidencia a transferência de energia entre plantas fotossintetizantes e consumidores. A negligência aos elementos relativos à transferência de energia no ecossistema foi apresentada por Gallegos, Jerezano e Flores (1994). Seus resultados indicaram, tendo por base entrevistas realizadas com docentes e revisão de livros didáticos, que a abordagem sobre as cadeias alimentares não toca a questão dos fluxos de energia.

Com efeito, nesse caso, o modelo apresentado pela professora pode ter dificultado a compreensão do conceito pelas crianças porque remete à sujeição e servidão de um organismo ao outro e não à rede trófica, ao encadeamento entre esses organismos e a transferência de energia. Ainda no tuno 38, a professora solicita aos alunos o nome do processo realizado pelas plantas para a produção de alimento. Nos turnos seguintes, dois alunos respondem prontamente: clorofila e fotossíntese - conceitos que circularam na sala de aula na ocasião do estudo das plantas. Para Vygotsky (1991), a expressão das palavras pode não significar compreensão dos conceitos, uma vez que pode ser uma ação mnemônica. No entanto,

os conceitos científicos disponibilizados na sala de aula são incorporados à consciência da criança e isso possibilita a formulação verbal do conceito, pois para Vygotsky, o uso de uma palavra, antes de sua apropriação, é essencial para a construção do conceito científico (ALMEIDA e GIORDAN, 2016, p. 783).

Nesse sentido, as manifestações dos estudantes não devem ser entendidas como sínteses da compreensão e apropriação do conceito científico, mas como uma etapa para esse processo. Os resultados indicam que as generalizações estabelecidas pelos estudantes se configuram como pensamentos por complexos, em vez de conceitos científicos. Vygotsky (2009, p. 180) ressalta que o "complexo se baseia em vínculos factuais que se revelam na experiência imediata. Por isso, ele representa, antes de mais nada, uma unificação concreta com um grupo de objetos com base na semelhança física entre eles". Desse modo, as relações que as crianças estabeleceram com os temas discutidos são mediadas por complexos.

Na sequência 2 - turnos de 42 a 79 -, a dinâmica discursiva mantém o mesmo caráter pragmático. Em alguns turnos, as crianças se expressam mais livremente. Em outros, os conceitos são apresentados, mas não há muitos indícios de que as crianças tenham compreendido a categorização dos organismos e suas funções na cadeia alimentar, de acordo com o conhecimento científico. Tendo em vista essas questões, a sequência 2 foi escolhida como fonte para análise da complexidade do ensino do conceito de cadeia alimentar e de outros conceitos relacionados. Também foram analisadas as dificuldades que a compreensão do modelo de cadeia alimentar traz consigo. Veja-se, então, a segunda sequência: 
Quadro 2. Produtores, herbívoros e carnívoros

\begin{tabular}{|c|c|c|c|}
\hline Turno & Participante & Discurso & Comentário \\
\hline 42 & Professora & $\begin{array}{l}\text { muito bem Carolina (...) é isso mesmo, } \\
\text { os vegetais realizam a fotossíntese e } \\
\text { produzem seu próprio alimento por isso } \\
\text { são chamados de produtores da cadeia } \\
\text { alimentar (...) agora me conta aqui (...) a } \\
\text { joaninha come apenas folhas (...) ela não } \\
\text { come carne, não come ovos, nada disso } \\
\text { (...) vocês sabem o nome que damos a ela? }\end{array}$ & $\begin{array}{l}\text { Escreve no quadro } \\
\text { a palavra produtor }\end{array}$ \\
\hline 43 & Laís & nome da joaninha? & \\
\hline 44 & Professora & $\begin{array}{l}\text { o nome que damos aos seres que só se } \\
\text { alimentam de vegetais? alguém sabe? }\end{array}$ & \\
\hline 45 & Laís & não sei & \\
\hline 46 & Alan & qual é? & \\
\hline 47 & Professora & $\begin{array}{l}\text { são os herbívoros (...) ok? todos os seres } \\
\text { que se alimentam apenas de vegetais } \\
\text { chamamos de herbívoros (...) e o leão? o } \\
\text { leão só come carne, não come vegetais (...) } \\
\text { como ele é chamado na natureza? }\end{array}$ & $\begin{array}{l}\text { Escreve a palavra } \\
\text { herbívoros no } \\
\text { quadro }\end{array}$ \\
\hline 48 & Vitor & CARNÍVORO... & \\
\hline 49 & Professora & muito bem! & \\
\hline 50 & Rian & ah eu sou carnívoro & \\
\hline 51 & & & Risos \\
\hline 52 & Professora & $\begin{array}{l}\text { você é carnívoro Rian? (...) mas você come } \\
\text { frutas, ovos e saladinhas não come? }\end{array}$ & $\begin{array}{l}\text { Escreve a palavra } \\
\text { carnívoro no } \\
\text { quadro }\end{array}$ \\
\hline 53 & Rian & como (...) como de tudo & \\
\hline 54 & Professora & $\begin{array}{l}\text { então pessoal (...) quem come carnes e } \\
\text { vegetais é o quê? }\end{array}$ & \\
\hline 55 & Vitor & não sei & \\
\hline 56 & Laís & $\begin{array}{l}\text { não é nem só carnívoro nem só herbívoro } \\
\text { né professora }\end{array}$ & \\
\hline 57 & Professora & $\begin{array}{l}\text { ISSO (...) nós chamamos esses seres de } \\
\text { onívoros ok? nós seres humanos somos } \\
\text { onívoros }\end{array}$ & $\begin{array}{l}\text { Escreve a palavra } \\
\text { onívoro no quadro. }\end{array}$ \\
\hline 58 & Vítor & onívoros & Repete a palavra \\
\hline 59 & Professora & $\begin{array}{l}\text { bom gente (...) já sabemos os nomes de } \\
\text { acordo com o tipo de alimentação e agora } \\
\text { voltando para a cadeia alimentar (...) } \\
\text { vamos imaginar aqui... lá no meu quintal, } \\
\text { eu tenho uma galinha, e essa galinha se } \\
\text { alimenta de... }\end{array}$ & $\begin{array}{l}\text { Desenha uma } \\
\text { galinha no quadro }\end{array}$ \\
\hline
\end{tabular}




\begin{tabular}{|c|c|c|c|}
\hline Turno & Participante & Discurso & Comentário \\
\hline 60 & Carolina & $\begin{array}{l}\text { ô professora, lá na minha avó tem pé de } \\
\text { couve e a galinha pulou a cerca e comeu } \\
\text { quase tudo }\end{array}$ & \\
\hline 61 & Professora & $\begin{array}{l}\text { pois então (...) galinha come quase tudo } \\
\text { (...) nesse exemplo aqui ela come minhoca } \\
\text { (...) come cupim (...) e pode comer a couve } \\
\text { também (...) então vamos ver se vocês } \\
\text { compreenderam, quais animais comem } \\
\text { apenas vegetais? }\end{array}$ & \\
\hline 62 & Laís & MINHOCA & \\
\hline 63 & Rian & GALINHA & \\
\hline 64 & Felipe & como a minhoca come professora? & \\
\hline 65 & Professora & $\begin{array}{l}\text { quais animais que nós vimos aqui que } \\
\text { comem tanto vegetais quanto carnes? }\end{array}$ & \\
\hline 66 & Rian & PORCO & \\
\hline 67 & Carolina & GALINHA & \\
\hline 68 & Alan & a gente professora & \\
\hline 69 & Professora & $\begin{array}{l}\text { isso }(. . .) \text { e quais animais se alimentam } \\
\text { apenas de carne? }\end{array}$ & \\
\hline 70 & Alan & ONÇA & \\
\hline 71 & Vitor & LEÃO & \\
\hline 72 & Camila & TIGRE & \\
\hline 73 & Felipe & professora (...) o urubu também & \\
\hline 74 & Alan & professora (...) jacaré, o jacaré... & \\
\hline 75 & Professora & $\begin{array}{l}\text { então voltando aqui (...) a galinha comeu } \\
\text { a minhoca e pode haver outros bichos que } \\
\text { vão entrar no galinheiro e comer a galinha } \\
\text { (...) não é? }\end{array}$ & \\
\hline 76 & Vitor & nós também comemos a galinha & \\
\hline 77 & Professora & $\begin{array}{l}\text { isso (...) nós também (...) então vocês } \\
\text { entenderam o que é cadeia alimentar? } \\
\text { fala pra mim Laís (...) o que é a cadeia } \\
\text { alimentar? }\end{array}$ & \\
\hline 78 & Laís & $\begin{array}{l}\text { ah é um bicho se alimentando do outro (...) } \\
\text { e das plantas também. }\end{array}$ & \\
\hline 79 & Professora & $\begin{array}{l}\text { ISSO (...) é uma relação onde uma espécie } \\
\text { se alimenta da outra l...) certo? agora } \\
\text { vocês estão em dupla porque vamos jogar } \\
\text { um bingo... }\end{array}$ & \\
\hline
\end{tabular}

Fonte: Autores. 
Como mostra o quadro 2, nesse episódio, com 37 turnos, a voz da professora apareceu em 14 turnos. Os alunos aparecem em 22 turnos, também nesse turno, na maioria das vezes, respondendo às perguntas da professora. As produções orais das crianças são curtas. A introdução de conceitos relacionados à cadeia alimentar e uma tentativa de uma síntese da aula marcam esse episódio.

No turno 42 a professora esclarece que, além da produção do seu próprio alimento, os produtores são fundamentais na realização da fotossíntese. Ainda nesse turno, ela incorpora elementos da realidade, citados no início da aula, para apresentar os conceitos de herbívoros e carnívoros. E ressalta que as joaninhas comem apenas folhas na tentativa de classificar esse inseto pelo alimento que consome. Contudo, as joaninhas são um dos maiores predadores no mundo dos insetos, pois alimentam-se de afídeos, moscas da fruta, pulgões, piolhos da folha e outros tipos de insetos, a maioria deles nocivos para as plantas. As crianças, possivelmente por considerar que a maioria dos insetos são herbívoros, não contestam a afirmação da professora, que pergunta a elas o nome que é dado à joaninha. A expectativa dela era que respondessem que eram herbívoros. Mas, diante da pergunta da professora, uma aluna, no turno seguinte, elabora outra questão na tentativa de compreender a pergunta da professora. Talvez estivesse pensando a aluna: afinal, o nome da joaninha não seria, joaninha? Essa pergunta evidencia o posicionamento responsivo da estudante.

A propósito, Bakhtin e o Círculo consideram a compreensão como um processo responsivo, de modo que "a compreensão está em função da capacidade de posicionamento e produção de réplicas frente ao enunciado do outro" (LIMA, 2019, no prelo). Desse modo, a compreensão pode ser interpretada como uma forma de diálogo em que a recontextualização das palavras produz sentidos à medida que se contrapõem a outras palavras (ALMEIDA, 2011). A responsividade no ato da compreensão está relacionada ao dialogismo, uma vez que ela se estabelece na relação entre os enunciados em busca de estabilizar sentidos às palavras alheias. Observa-se, na pergunta da estudante, um posicionamento claro que foi orientado pelo nome do animal (joaninha) e não pela categoria que ele deveria ter sido representado o qual foi enunciado pela professora (herbívoro). Considerando-se que o dialogismo está orientado tanto pela relação entre o enunciado e seu objeto quanto pelas relações entre os enunciados dos sujeitos que se comunicam (LIMA; GIORDAN, 2017), a interação mostra um diálogo em que o enunciado da estudante orienta-se pelo enunciado da professora, que é baseado em um elemento trivial do objeto discursivo, no caso o nome do animal.

Além disso, a resposta da estudante indica a dificuldade das crianças em operar com instrumentos lógicos e abstratos, que são característicos nas operações com conceitos científicos. Tal dificuldade está relacionada com o estágio real de desenvolvimento dessas crianças. Paralelamente, a estudante retoma o vínculo real e concreto dominado por todos o nome do inseto. Esses fatos fortalecem a interpretação de que as crianças estão produzindo complexos para compreender e mediar o tema cadeia alimentar.

No turno 44, a professora reelabora a pergunta demonstrando a necessidade de negociar os sentidos das palavras para que elas possam ser compreendidas de acordo com os objetivos educacionais. Nessa pergunta a professora explicita quão 
exata deve ser a resposta. Diante da negativa dos alunos, ela define o conceito no turno 47. Lima e colaboradores (2015) chamam a atenção para a relevância dada às definições e exemplos nas aulas de Ciências e ressaltam que

memorizar uma definição correta não garante a compreensão das muitas relações nelas envolvidas. Afinal, a aprendizagem de conceitos é algo muito mais complexo do que a simples proposição de definições consagradas em textos didáticos, em glossários e notas de aulas (LIMA; AGUIAR; CARO, 2011, p. 857)

Para esses autores, as definições não deveriam ser o ponto de partida no processo de ensino. A definição é momento de síntese, de compreensão sintética, acabada e formal (LIMA; AGUIAR; CARO, 2011). Nesse sentido, elas devem ser apresentadas com ferramentas mediacionais capazes de articular e sintetizar os novos sentidos elaborados durante o processo de ensino e aprendizagem.

No turno 48, um aluno responde à pergunta da professora mostrando familiaridade com a palavra. Mas, no turno 50, outro aluno se intitula "carnívoro". Possivelmente, para ele, a sua preferência por carnes definia a classificação. As crianças acharam graça na afirmação do colega porque para elas a identificação possivelmente soava como uma comparação aos animais selvagens.

Prosseguindo a aula, no turno 52, a professora se opõe às ideias do aluno, argumentando que a classificação alimentar estava para além das preferências de cada um. Então, explica-lhes que, além de carne, ele come também vegetais.

Já no turno 54, o objeto de negociação é o conceito de “onívoros". A pergunta mais uma vez, induz a uma única resposta. Em adição, no turno 56, uma aluna, orientando-se para a pergunta da professora (turno 54), afirma que quem se alimenta de vegetais e carnes não é só carnívoro ou herbívoro. Se, por um lado, essa reposta vai em direção a um conceito além de carnívoro e herbívoro, por outro, faltam elementos que permitam a aluna identificar e inferir sobre relações alimentares e organismos onívoros.

Mais adiante, no turno 59, a professora mostra, mais uma vez, sua preocupação com as definições salientando: “já sabemos os nomes de acordo com o tipo de alimentação". Como se vê, usando a primeira pessoa no plural (nós), a professora se inclui no processo de ensino e aprendizagem, neste caso, das definições. Contudo, essa inclusão é falaciosa uma vez que a relação de poder entre os sujeitos é delimitada pela função social da professora, ela deixa claro que os sentidos ali expressos devem ser correspondentes ao conhecimento científico. Já os sentidos produzidos pelas crianças podem ter outras correspondências. Resultado que já foi evidenciado em outros trabalhos (DUCROT apud FONTANA, 2000; ALMEIDA e GIORDAN, 2016).

Ainda nesse turno, a professora retoma e sintetiza alguns conceitos trabalhados na aula. Depois de categorizar os organismos conforme relações alimentares (turnos anteriores), ela dá prosseguimento à aula retomando o conceito de cadeia alimentar. Dessa forma, a discussão de cadeia alimentar pode parecer às criança desvinculada de todos os conceitos anteriormente apresentados, pois a retomada ocorre por meio de uma ruptura, uma síntese que não dialoga com todos os conceitos que circularam em sala de aula. Para essa síntese, a professora recorre, 
mais uma vez, a uma narrativa que destaca situações próximas às experiências das crianças para abordar o conceito de cadeia alimentar. No turno 60, uma aluna fala de uma experiência pessoal ocorrida na casa da sua avó: uma galinha comeu os pés de couve. A professora, turno 61, não ignora totalmente o discurso da aluna e usa o comentário para prosseguir com a agenda da aula. Então, pergunta às crianças, quais animais comiam apenas vegetais, visando à compreensão literal dos conceitos pelas crianças. Contudo, nos turnos seguintes, elas respondem: minhoca e galinha. É importante destacar que as minhocas são animais que se alimentam de detritos de várias origens tais como sementes, folhas e algumas espécies de invertebrados. As respostas das crianças demonstram que a galinha pode se alimentar de animais e plantas, contudo isso não foi problematizado pela docente. A professora segue adiante perseguindo o ensino de um modelo de cadeia alimentar no qual um organismo se alimentar de outro e busca estabelecer uma relação direta e linear entre os organismos. Ignorar os comentários e respostas das crianças parece ser uma estratégia da professora para manter sua explicação e controle da turma e do modelo de cadeia alimentar que se ajusta ao conceito que ela define. Segundo Odum (2004. p. 97), "a população de uma dada espécie pode ocupar um ou mais do que um nível trófico de acordo com a fonte de energia realmente assimilada". Os exemplos da professora possuem poucas variações das relações entre os organismos e estão baseados em um modelo de explicação acabada. Ela apresenta os conhecimentos científicos por meio de definições prontas e de um mecanismo de transferência de conhecimentos.

Aliás, essa estratégia da professora de ignorar as respostas dos estudantes é tão marcante que ocorre até em respostas antagônicas, como nos turnos 63 e 67. Por exemplo: Rian classifica a galinha como herbívoro e a Carolina como onívoro. Tal fato, demonstra que a interação estabelecida pela professora não se fundamenta na troca de informações ou levantamento de concepções dos estudantes. $\mathrm{Na}$ verdade, o que se observa é uma simulação em que as vozes das crianças são encaixadas em seu discurso preparado acerca do conteúdo. Essa interpretação é fortalecida pelo fato de haver poucas variações na historicidade da narrativa que foram determinadas pelas crianças. Quando as variações na narrativa ocorrem, não há desencadeamento comunicativo e a professora tenta, o mais rápido possível, retomar a narrativa planejada.

Passando ao turno 64, um aluno pergunta sobre "como" a minhoca come. Sua pergunta foge aos propósitos da aula, mas ele encontra sentido para fazê-la. Afinal, a discussão girava no âmbito das relações alimentares: "quem come quem" e "como esses organismos comem e são comidos".

No turno 65, a professora pergunta às crianças quais os animais, citados na aula, comem vegetais e carnes. As crianças respondem: porco, galinha e pessoas. Assim, eles interpretam que porco, galinha e pessoas estão na mesma categoria. Isso indica que os estudantes entenderam que todos esses animais são seres onívoros. Ressalta-se, porém, que a professora classificou apenas os seres humanos como onívoros (turno 57), indicou que a galinha também come diversos tipos de alimento (turno 61) e não mencionou o porco. Desse modo, é evidente que há uma compreensão responsiva dos estudantes, pois conseguem agrupar animais que possuem características similares na mesma classificação, ainda que essa classificação 
não tenha sido realizada explicitamente para todos os casos. Entende-se que a compreensão responsiva das crianças não é suficiente para evidenciar a apropriação dos conceitos científicos. Isso carece do pleno domínio terminológico associado ao seu uso arbitrário. Tais condições que não aparecem nas interações descritas.

Prosseguindo a análise, no turno 69, a professora solicita às crianças exemplos de espécies que se alimentam apenas de carne. Elas respondem: onça, leão, tigre, jacaré e urubu. É importante observar que os primeiros carnívoros citados pelas crianças são "grandes predadores". Durante essa interação, é possível identificar o movimento descendente dos conceitos científicos indicado por Vygotsky (2009). Ele é iniciado com a pergunta da professora que faz referência ao conceito (abstrato) e desenvolvido com as respostas das crianças, baseadas em elementos concretos. Os exemplos dos estudantes incorporam elementos concretos ao "conceito" (carnívoro) que contribuem para a sua consolidação.

Dos animais citados, o urubu não tem uma dieta tão restritiva quanto os outros porque, assim como a minhoca, é um animal detritívoro. Como os animais detritívoros promovem o início de um processo de reciclagem da matéria orgânica, facilitando o trabalho de decomposição que bactérias e fungos desempenham, a menção a esses animais pelas crianças poderia ser problematizada pela professora. Por outro lado, como o papel desses animais não foi discutido com as crianças, elas podem pensar que ratos e urubus são responsáveis pelo processo de decomposição da matéria orgânica. É possível inferir, na análise desse evento, que as relações alimentares são observadas como a fotografia de uma situação particular em um determinado momento. Assim, para as crianças, a galinha é um herbívoro quando come vegetais, mas pode ser classificada como um animal onívoro quando pensam na ave comendo minhoca. Ressalta-se que novamente as interações das crianças estão baseadas exclusivamente em vínculos concretos, o que pode indicar a produção de um complexo. "O mais importante para construir um complexo é o fato de ele ter em sua base não um vínculo abstrato e lógico, mas um vínculo concreto e factual entre elementos particulares que integram sua composição" (VIGOTSKI, 2009, p. 180). A variação na classificação de um mesmo animal associada aos vínculos factuais, concretos e fortuitos fortalecem a intepretação da produção de complexos.

Nessa aula, as palavras são fluidas e os conceitos também, fato que é comum durante a produção de sentidos. O tipo de abordagem escolhida pela professora não favorece a compreensão do conceito de cadeia alimentar como uma construção teórica e atemporal, isto é, como modelo.

No turno 75, a professora volta à síntese do conceito recorrendo apenas à linguagem verbal para estabelecer as relações. Ela inclui, na cadeia, apenas a galinha, a minhoca e outro animal que pode comer a galinha, indicando claramente a omissão dos produtores. Nesse evento, predomina uma concepção dos seres vivos que corrobora os estudos de Driver e colaboradores (1994). Segundo esses autores as crianças postulam que as plantas produzem alimentos em benefício dos animais e das pessoas e que os animais existem em função dos seres humanos. $\mathrm{Na}$ sequência, no turno 76, um aluno diz que comemos a galinha. Apesar da prevalência dos animais na cadeia alimentar e ao caráter utilitário dado a eles, a menção ao ser humano é uma observação importante que poderia levar a reflexão do impacto do ser humano na cadeia alimentar. 
Por fim, nos turnos 78 e 79, observa-se, nas idas e vindas das palavras, que o significado atribuído à cadeia alimentar permanece no viés de dependência alimentar entre presas e predadores em ordem hierárquica.

\section{CONSIDERACְÕES FINAIS}

As reflexões apresentadas neste trabalho tiveram a intenção de analisar as estratégias utilizadas por uma professora no ensino do conceito de cadeia alimentar e os sentidos e significados produzidos pelas crianças em uma aula de ciências nos anos iniciais do Ensino Fundamental.

A análise dessa aula mostra que a professora utiliza, pelo menos, quatro estratégias para ensinar o conceito às crianças. A primeira delas é uma apresentação verbo-visual do conceito. Outra estratégia diz respeito ao uso de situações próximas às experiências das crianças. Também, as perguntas da professora constituem uma proposta de intervenção muito frequente em sala de aula. A quarta estratégia refere-se ao uso de uma narrativa rígida sem a possibilidade de grandes desvios, comprometendo a interação verbal entre a professora e os estudantes.

A análise das respostas das crianças dos dois episódios de ensino (Quadro 1 e 2) permite apreciar a diversidade de maneiras pelas quais as crianças significam a linguagem nas aulas de Ciências e interpõem elementos mediadores para interagir com o tema da aula. Assim, é necessário refletir sobre os sentidos e significados que permeiam e mediam os conceitos, haja vista que a linguagem não é neutra nem transparente. Conforme Bakhtin, os atos de fala não são simples decodificação ou interpretação, são modos de compreensão, de produção de contrapalavras, atos de negociação e constituição de sentidos. Nessa perspectiva, os conceitos científicos serão sempre um desafio para o ensino dos professores e compreensão dos alunos.

Posto isso, observou-se no episódio 2 a tentativa da professora de cercar o conceito científico sobre cadeia alimentar interpondo exemplos diferentes, um caso em que a dialogia se manifesta colaborativamente em prol da estabilização do sentido da palavra. Contudo, a dialogia também se manifestou por meio de disputas acerca dos sentidos das palavras, como ocorrera com a significação do termo cadeia alimentar (turnos 6, 7 e 8) e com a classificação da galinha como herbívoro ou onívoro (turnos 63 e 67).

Em relação ao conceito de cadeia alimentar, alguns aspectos se destacaram no estudo ao analisar os turnos da aula. A abordagem da professora sugere e encaminha as explicações sobre cadeia alimentar como um processo linear entre os diferentes níveis tróficos de um ecossistema. Ressalta-se, também, que a ideia de um equilíbrio ambiental é predominante porque não se reconhece que uma população pode ser afetada com o declínio de outra. As relações tróficas destacadas mencionam, segundo a professora, especialmente, a relação de presa e predador e de extermínio de acordo com as crianças. As ilustrações da professora não aprofundam o tema porque o significado atribuído às setas e imagens só se refere à ordem em que os organismos estão localizados na cadeia trófica. Devido à ausência de discussão sobre o que é ecossistema, como se dá o fluxo de energia, a compreensão de cadeia alimentar fica comprometida. O conceito fica restrito à interdependência alimentar entre alguns organismos da cadeia e não ao sistema 
dinâmico dos ambientes. Assim, em uma primeira análise, pode-se considerar que a discussão desse conceito em sala de aula passa simplesmente pela formação da professora. No entanto, é preciso destacar que a maioria dos livros didáticos apresenta a ideia de natureza em equilíbrio e reforça um modelo de cadeia alimentar pelo viés linear. Esse é um aspecto que precisa ser levado em consideração, pois se há obstáculos para o ensino desse conceito, a maneira como os livros apresentam essa discussão parece auxiliar pouco os professores na mediação do conteúdo. Retomando a atuação da professora em estudo, observou-se que, em uma mesma aula, vários conceitos foram apresentados às crianças, mas não fica claro se elas compreenderam o papel dos organismos citados na cadeia alimentar e a necessidade de reagrupá-los por características que os identificam. Os resultados indiciam que enquanto a professora atua com a mobilização de conceitos científicos, as crianças produzem complexos, que mediam suas interações com o conteúdo.

As análises indicaram que os estudantes estão no segundo estágio do desenvolvimento de conceitos, que, de acordo com Vygotsky (2009), é denominado de pensamento por complexos. Nesse processo, os estudantes usufruem de conceitos espontâneos acerca dos animais, indicando que os conceitos espontâneos foram mobilizados como suporte para o desenvolvimento dos relativos ao tema cadeia alimentar, ainda que, nem sempre, de modo corroborativo. É importante ressaltar que, embora os estudantes estivessem orientados por conceitos científicos mobilizados pela professora, eles não interagiam com os conteúdos de forma abstrata e lógica, mas de forma concreta, factual e fortuita. A mobilização do conceito científico pela professora e dos complexos pelos estudantes parece indicar uma contradição frequente nas aulas de Ciências do Ensino Fundamental I e, por isso, é um tema que pode ser aprofundado em investigações futuras.

É preciso lembrar que o papel dos modelos científicos, como mediadores entre o ser humano e a realidade, é de representar fenômenos difíceis de compreender, principalmente tratando-se de crianças nos anos iniciais de escolarização. Dessa maneira, é desejável que as crianças sejam ouvidas na discussão dos conceitos relativos à cadeia alimentar, ao mesmo tempo em que é preciso organizar atividades que os ajudem a vislumbrar a distância existente entre os conceitos (ou complexos) usados para representar o mundo natural e a realidade em si. Uma maneira de levar as crianças a compreenderem os conceitos e o modelo é discutir com elas mais de uma situação, mais de um modelo conceitual que representa o mesmo fenômeno, discutir as diferentes formas de representar as relações alimentares entre os membros de uma comunidade biológica a partir de comparações e análises. A diversificação de situações pode promover a aumento de relações lógicas e abstratas e contribuir para a aprendizagem de conceitos científicos. Outra possibilidade de discussão desse conceito com as crianças é a proposição de trabalhos de campo e abordagens investigativas. Em última análise, o ensino baseado em situações reais pode propiciar aos estudantes reflexões mais complexas e maior compreensão dos conceitos.

As implicações deste estudo indicam a necessidade de escutar atentamente as manifestações das crianças para que os professores possam compreender como os alunos interagem com as ideias apresentadas. Além de corrigir interpretações equivocadas, ao promover o diálogo, o professor também pode identificar 
formas típicas do pensamento humano (conceitos espontâneos, pensamento por complexos e conceito científico) e atuar em prol do desenvolvimento de estruturas mais complexas, como o conceito científico. Os resultados desta investigação demandam também que a formação docente e a produção dos livros didáticos apresentem às professoras as concepções das crianças em relação a interação entre os organismos e os desafios para ensinar o conceito de cadeia alimentar.

\section{REFERÊNCIAS}

ALMEIDA, S. A. A. Interações e práticas de letramento mediadas pela revista Ciência Hoje das Crianças em sala de aula. Tese - Universidade de São Paulo, São Paulo, 2011.

ALMEIDA, S.A.A; GIORDAN, M. A apropriação do gênero de divulgação científica pelas crianças: fragmentos de um percurso. Revista Brasileira de Pesquisa em Educação em Ciências, p.773797, 2016. https://periodicos.ufmg.br/index.php/rbpec/article/view/4495

BRASIL. Ministério da Educação. Secretaria de Educação Fundamental. Parâmetros curriculares nacionais: ciências naturais. 2000.

BAKHTIN, M. Estética da criação verbal. São Paulo: Martins Fontes, 2000.

BAKHTIN, M. Marxismo e filosofia da linguagem. São Paulo: Hucitec, 1981.

CASTRO, D. R.; BEJARANO, N. R. R. Conhecimentos Prévios sobre Seres Vivos dos Estudantes das Séries Iniciais da Cooperativa de Ensino de Central - COOPEC- BA. Revista Brasileira de Ensino de Ciência e Tecnologia, vol. 6, núm. 1, 2013. http://dx.doi.org/10.3895/S1982873X2013000100002

DRIVER, R.; SQUIRES, A.; RUSHWORTH, P.; \& WOOD-ROBINSON, V. (1994). Nutrition. In: DRIVER R.; SQUIRES A.; RUSHWORTH, P.; \& WOOD-ROBINSON, V. (ed.). Making Sense of Secondary Science: Research into Children's Ideas (pp.27-35). New York: Routledge.

FONTANA, R. A. C. A elaboração conceitual: a dinâmica das interlocuções na sala de aula. In: SMOLKA, A. L.; GÓES, M. C. (org.). A linguagem e o outro no espaço escolar: Vygotsky e a construção do conhecimento. Campinas, Papirus, 2000.

GALLEGOS, L; JEREZANO, M. E.; FLORES, F. Preconceptions and Relations Used by Children in the Construction of Food Chains. Journal of research in science teaching, v. 31, n. 3, p. 259272, 1994. https://doi.org/10.1002/tea.3660310306

GIORDAN, M.; SILVA NETO, A. B.; AIZAWA, A. Relações entre Gestos e Operações Epistêmicas Mediadas pela Representação Estrutural em Aulas de Química e suas Implicações para a Produção de Significados. Química nova na escola, v. 37, p. 82-94, 2015. http://dx.doi.org/10.5935/01048899.20150021

GÓES, M. C. R. A abordagem microgenética na matriz histórico-cultural: Uma perspectiva para o estudo da constituição da subjetividade. Cadernos Cedes, n. 50, 2000. http://dx.doi.org/10.1590/ S0101-32622000000100002

HARTWEG, B.; BIFFI, D.; FUENTE, Y.; MALKOC, U.; PATTERSON, M. E.; PEARCE, E.; STEWART, M. A.; WEINBURGH, M. Peruvian Food Chain Jenga: Learning Ecosystems with an Interactive Model. School Science and Matematics, 117, 6, 2017. https://doi.org/10.1111/ssm.12230 
IBRAIM, S. S.; MENDONÇA, P. C. C.; JUSTI, R. S. Contribuições dos Esquemas Argumentativos de Walton para análise de argumentos no contexto do Ensino de Ciências. Revista Brasileira de Pesquisa em Educação em Ciências, v. 1, p. 159-185, 2013. https://periodicos.ufmg.br/index. $\mathrm{php} / \mathrm{rbpec} / \mathrm{article} / \mathrm{view} / 4256$

LACREU, L. I. - Ecologia, Ecologismo e Abordagem Ecológica no Ensino das Ciências Naturais: Variações sobre um Tema. In: WEISSMANN, H. (org.) - Didática das Ciências Naturais contribuições e reflexões. Porto Alegre: Ed. Artmed, 1998.

LEAL, M. C.; GOUVÊA, G. Narrativa, mito, ciência e tecnologia: o ensino de ciências na escola e no museu. Ensaio Pesquisa em Educação em Ciências (Belo Horizonte), v. 2, n. 1, p.5-33, 2000. http://dx.doi.org/10.1590/1983-21172000020103

LIMA, M.E.C.C.; AGUIAR O. J.; CARO, M. A formação de conceitos científicos: reflexões a partir da produção de livros didáticos. Ciência \& Educação, Bauru, v. 17, n. 4, p. 855-871, 2011. http:// dx.doi.org/10.1590/S1516-73132011000400006

LIMA, G. S. O conceito de compreensão em Bakhtin e no Círculo: reflexões para pensar o processo educativo. Bakhtiniana: Revista de estudos do discurso, v. 14, n. 4, 2019 no prelo.

LIMA, G. S.; GIORDAN, M. Características do discurso de divulgação científica: implicações da dialogia em uma interação assíncrona. Investigações em Ensino de Ciências, 22(2), 83-95. http://dx.doi.org/10.22600/1518-8795.ienci2017v22n2p83

MEHAN, H. Learning lessons: social organization in the classroom. Cambridge, Massachusetts and London: Harvard University Press, 1979.

MORTIMER, E. F.; SCOT'T, P. Atividade discursiva nas salas de aula: uma ferramenta sociocultural para analisar e planejar o ensino. Investigações em Ensino de Ciências, v.7, n. 3, 2002. https:// www.if.ufrgs.br/cref/ojs/index.php/ienci/article/view/562

ODUM, E.P. Fundamentos da ecologia. Lisboa: Fundação Clouste Gulbenkian, 2004.

OLIVEIRA, V. L. B.; PAZ, A. M.; SILVA; I. A. M.; ALVES FILHO, J. P. Cadeia alimentar: modelos e modelizações no ensino de ciências naturais. Atas IV Encontro Nacional De Pesquisa Em Educação Em Ciência (ENPEC), 2003.

PAZ, A. M.; ABEGG, I.; ALVES FILHO, J. P.; OLIVEIRA, V. L. B. Modelos e modelizações no ensino: um estudo da cadeia alimentar. Ensaio, v. 8, n.2, p. 133-146. 2006. http://dx.doi. org/10.1590/1983-21172006080205

PEREIRA, B. C.; CARVALHO, F. A. As ilustrações sobre teias e cadeias alimentares como formadoras de conceitos ecológicos em livros didáticos de ensino fundamental. Atas do IX Encontro Nacional de Pesquisa em Educação em Ciências -IX ENPEC, Águas de Lindóia, SP, 2013.

PEREIRA, B. L. Recepção e uso de livro de apoio ao professor dos anos iniciais: um estudo de caso do livro "Trilhas para Ensinar Ciências para Crianças" - Dissertação - Universidade Federal de Ouro Preto - Mestrado Profissional em Ensino de Ciências - MPEC, 2017.

SILVA, M. E.; MASKIEWISCZ, A. C. Understanding Causal Relationships in Food Webs Using "Data-Rich Problem". The American Biology Teacher, 78(8), 635-641, 2016. http://dx.doi. org/10.1525/abt.2016.78.8.635

VIGOTSKI, L. S. Pensamento e linguagem. São Paulo: Martins Fontes, 1991. 
VYGOTSKY, L. S. A construção do pensamento e da linguagem. São Paulo: WMF Martins Fontes, 2009.

WEBB, P.; BOLTT, G. Food chain to food web: a natural progression? Journal of Biological Education, 24:3, 187-190, http://dx.doi.org/10.1080/00219266.1990.9655139

\section{NOTAS}

1 De acordo com Bakhtin (1981), o signo é um elemento capaz de representar e substituir algo externo, sendo essencialmente ideológico e capaz de refletir e refratar outra realidade que está além de seus limites. Se reduzirmos o termo cadeia alimentar aos seus elementos constituintes, não encontraremos nada além de uma ordenação de letras. Contudo, esse signo representa e é constituído pela significação de um conceito científico, que, por sua vez, está orientado de determinada forma (Ciência) para a realidade, por isso é ideológico.

2 Na transcrição dos eventos foram usados o padrão ortográfico, os parênteses com reticência (...) para pausas e letras maiúsculas para ênfases, além de nomes fictícios para preservar a identidade dos sujeitos da pesquisa.

Submetido em 15/04/2019

Aprovado em 15/10/2019

\section{Contato:}

Rua Gênova, 125 - Bairro Cachoeirinha

CEP 31.130-210 - Belo Horizonte, MG - Brasil 